\title{
Análise heurística do isomorfismo institucional na escolha dos artefatos de contabilidade gerencial
}

\author{
Aucione Aparecida Barros Guimarães ${ }^{1}$ \\ Roberto Miranda Pimentel Fully ${ }^{2}$ \\ Deise Freitas ${ }^{3}$ \\ Elenice Maria da Silva ${ }^{4}$
}

\section{Resumo}

Este trabalho teve como objetivo investigar a influência do isomorfismo institucional na adoção dos artefatos de contabilidade gerencial. Através de um estudo de caso, os dados foram coletados por meio de uma entrevista realizada em uma Cooperativa de Crédito do município de Caratinga, Minas Gerais. Procurou-se entender até onde a necessidade de se assemelhar com uma outra cooperativa interfere na adoção dos artefatos gerenciais. Padrões ditados têm sido geralmente copiados, esses fatores podem estar entrelaçados a pressões isomórficas. Diante do objetivo proposto, o trabalho caracterizase como descritivo e utiliza o procedimento de survey. A resposta esperada é a de reafirmar a suposição da teoria institucional e entender se o método já utilizado se aplica à outras organizações. Quanto ao objetivo específico, foi identificado que a Cooperativa de Crédito utiliza doze dos vinte artefatos apresentados. Com relação aos Métodos e Sistemas de Custeio, utiliza o ABC, Custo Meta, Custeio por Absorção e Custeio Variável. Entre os Métodos de Avaliação e Medidas de Desempenho apresentados, utiliza o Benchmarking, Valor Presente, Análise do Ponto de Equilíbrio e Moeda Constante. Das Filosofias e Modelos de Gestão, utiliza o Orçamento, Simulações, Descentralização, Teoria das Restrições e o Balanced Scorecard. Quanto à influência do isomorfismo institucional na adoção dos artefatos gerenciais, a partir dos resultados, pode-se concluir que existem traços de isomorfismo normativo decorrente da profissionalização, contudo esta forma de pressão isomórfica não é determinante na adoção dos artefatos de contabilidade gerencial. $\mathrm{O}$ que na verdade pode-se observar em relação aos artefatos, é que eles não sofrem com fatores isomórficos, considerando que existe uma incerteza entre os representantes de qual método é utilizado. Os testes mostraram tendências de isomorfismo normativo em relação à formação dos presentes, entretanto, dada a não apresentação clara dos artefatos gerenciais pela Cooperativa de Crédito, não foi possível confirmar o isomorfismo nas técnicas.

Palavras-chave: Isomorfismo, contabilidade gerencial, artefatos gerenciais, teoria institucional, cooperativa.

\section{Heuristic analysis of institutional isomorphism in the choice of management accounting artifacts}

\footnotetext{
Abstract

1 Faculdades Integradas de Caratinga (MG). aucioneguimaraes@gmail.com

2 Faculdades Integradas de Caratinga (MG). rfully@gmail.com

3 Faculdades Integradas de Caratinga (MG). deise freitas202@hotmail.com

${ }^{4}$ Faculdades Integradas de Caratinga (MG). elenice silvamar@hotmail.com
} 
This work aimed to investigate the influence of institutional isomorphism on the adoption of management accounting artifacts. Through a case study, the data were collected through an interview conducted at a Credit Cooperative in the municipality of Caratinga, Minas Gerais. We sought to understand how far the need to resemble another cooperative interferes with the adoption of managerial artifacts. Dictated patterns have generally been copied, these factors may be entangled with isomorphic pressures. In view of the proposed objective, the work is characterized as descriptive and uses the survey procedure. The expected response is to reassert the assumption of institutional theory and to understand whether the method already used applies to other organizations. Regarding the specific objective, it was identified that the Credit Cooperative uses twelve of the twenty artifacts presented. With regard to Costing Methods and Systems, it uses ABC, Target Cost, Absorption Costing and Variable Costing. Among the Valuation Methods and Performance Measures presented, it uses Benchmarking, Present Value, Balance Point Analysis and Constant Currency. From Philosophy and Management Models, it uses the Budget, Simulations, Decentralization, Restriction Theory and the Balanced Scorecard. As for the influence of institutional isomorphism on the adoption of managerial artifacts, it can be concluded from the results that there are traces of normative isomorphism resulting from professionalization, but this form of isomorphic pressure is not determinant in the adoption of management accounting artifacts. What we can actually observe in relation to the artifacts is that they do not suffer from isomorphic factors, considering that there is an uncertainty among the representatives of which method is used. The tests showed normative isomorphism tendencies in relation to the present training, however, given the lack of clear presentation of the managerial artifacts by the Credit Union, it was not possible to confirm the isomorphism in the techniques.

Keywords: Isomorphism, managerial accounting, managerial artifacts, institutional theory, cooperative.

\section{INTRODUÇÃO}

Padrões ditados têm sido geralmente copiados, e podem estar entrelaçados a pressões isomórficas. DiMaggio e Powell (2005) entendem que o isomorfismo compõe um processo que influência uma organização a se assemelhar a outras do mesmo modelo ambiental. Assim segundo os autores, elas passam a se tornar menos competitivas e eficientes, e mais semelhantes.

Associado a essas pressões se encontra o uso de artefatos de contabilidade gerencial. Guerreiro, Frezzati e Casado (2006) citam que a prática não acompanha o mesmo galgar da teoria. Havendo assim uma quebra de continuidade entre teorias e práticas de Contabilidade Gerencial.

Boya (2012) realizou uma pesquisa voltada para a Nova Sociologia Institucional, afim de descobrir qual "A influência do isomorfismo institucional na adoção dos artefatos de Contabilidade Gerencial", feita em duas empresas de grande porte da cidade de Cataguases (MG). 
Mendes (2015), em seu artigo de revisão sobre "Ignorância Organizacional: Desafios e Oportunidades de Pesquisa", discorre sobre os efeitos que cercam a teoria da ignorância. Utilizando o método estruturado Proknow-C com 24 artigos, discute sobre o tema Ignorância Organizacional.

Alinhando as pesquisas de Boya e Mendes (2012 e 2015), foi proposto estudar o problema na Cooperativa de Crédito no município de Caratinga e responder à seguinte questão: qual influência isomórfica sofrida na adoção dos artefatos de contabilidade gerencial e como circulam as informações dentro do ambiente coorporativo? Assim, este trabalho teve como objetivo investigar a influência do isomorfismo institucional na adoção dos artefatos de contabilidade gerencial. Para se alcançar resultados buscou-se como objetivo específico, identificar os artefatos de contabilidade gerencial utilizados pela cooperativa analisada.

Diante do objetivo proposto, o trabalho caracteriza-se como descritivo e utiliza o procedimento de survey. A resposta esperada é a de reafirmar a suposição da teoria institucional e entender se o método já utilizado se aplica a outras organizações.

\section{CONTABILIDADE GERENCIAL}

Conforme foi citado por Atkinson, Banker, Kaplan e Young (2000, p. 812), a contabilidade gerencial pode ser entendida como o resultado da produção de informação do tipo financeira e operacional, afim de direcionar os gestores no processo de tomada de decisão, no âmbito operacional e de investimentos.

Padoveze (2000) cita que a contabilidade gerencial é principalmente usada nas organizações, servindo de ferramenta para toda administração, e por ela atender diretamente aos usuários internos, as informações tendem se direcionar de acordo com as necessidades, contribuindo para a tomada de decisão.

Segundo Guerreiro et al. (2006), a principal missão da contabilidade gerencial é fornecer informações precisas, afim de direcionar os gestores para que eles possam aumentar os resultados da organização.

\section{TEORIAS ECONÔMICAS IMPORTANTES PARA A CONTABILIDADE GERENCIAL}


Conhecida como Teoria matemática da comunicação, foi estudada Claude Elwool Shannon e Warren Weaver, em 1940, afim de tratar de problemas relacionados ao armazenamento e circulação das informações. Segundo Coutinho (2004), esses autores consideraram comunicação como um problema, embasando em estatísticas.

A teoria da informação estima a exatidão e o êxito da corrente informativa, procurando segundo Pelegrini (2009), servir de referência a para qualquer esfera da comunicação.

Horngren (1985), afirma que a teoria da decisão é vista como uma estrutura confusa de estudos criados por estatísticos, matemáticos e psicólogos, que desejam firmar regras para a tomada de decisão e traçar metodicamente as variáveis que afetam as escolhas, assim o papel da contabilidade está inserido no processo decisório.

Segundo Kerlinger (1986), mensuração é um jogo de objetos e números, de acordo com normas, como uma função matemática. Evidenciar uma norma é interpretar uma função, cada componente de um conjunto, o domínio, corresponde a um único componente de outro conjunto

Segundo Hansen e Mowen (2010), a teoria das restrições (TOC) identifica que a prática de qualquer organização está fixada por suas restrições. Relacionado a quesitos operacionais, todo agrupamento tem pelo menos uma restrição que fixa sua produção. Tem como objetivo a abordagem da melhoria contínua.

\section{ARTEFATOS DE CONTABILIDADE GERENCIAL APLICADOS}

Segundo Martins (2003), o custeio por absorção é o método derivado da aplicação dos princípios contábeis geralmente aceitos, e baseia- se em apropriar os custos de produção aos bens produzidos. Já os gastos com produção são apropriados para todos os serviços e produtos. Cardoso, Mário e Aquino (2007) afirmam que a partir desse método é possível acatar todos os fins societários e fiscais, facilitando para um esclarecimento legal do resultado.

Martins (2003), afirma que esse método aloca aos custos de produção do período somente os custos variáveis incorridos, sendo que os fixos ficam separados e são mantidos como despesa do período, sendo diretamente transferidos para o Resultado. Já os estoques, recebem os custos variáveis somente como consequência.

Derivando da necessidade de ser reconhecer o custo real, surgi o conceito de custo padrão. De acordo com Padoveze (2000), o cálculo dessa forma de custeio é feito 
a partir de acontecimentos futuros de custos ou acontecimentos desejados de custos que podem acontecer ou não na organização.

Para Atkinson et al. (2000), o custeio baseado em atividades, amplia o plano que desenvolve a ideia de direcionadores de custo que liga, de forma direta, as atividades realizadas aos produtos fabricados. Esses direcionadores de custos servem para medir o consumo médio ocorrido, das atividades realizadas, em relação aos produtos. Assim, os custos das atividades realizadas são apropriados aos produtos, na medida do consumo que os produtos exerceram, em relação as atividades.

Para Martins (2003), esse método consiste em uma ferramenta que possibilita a identificação dos custos através de uma análise das atividades que foram executadas, relacionando-as ao produto.

O custo alvo ou custo meta como também é conhecido, foi definido por Hansen e Mowen (2010), como sendo a diferença entre o preço de venda primordial para se apreender uma parte previamente determinada de mercado e o lucro desejado por unidade. Esse plano afirma que a redução do custo deve ser feita ainda no projeto do produto, sendo nessa fase que os maiores montantes dos custos são alocados.

Cardoso et al. (2007) acreditam que padronizar as práticas de custeio dos produtos amparados pelas organizações privadas e desenvolver técnicas de custeio que se tornassem mais úteis ao processo de precificação.

\section{MÉTODOS DE AVALIAÇÃO E MEDIDAS DE DESEMPENHO}

Segundo TenHave (2003), o benchmarking pode ser conceituado como a confrontação entre os processos e desempenhos ocorridos em distintas organizações. E a partir disso possam gerar formam de melhorar os processos.

Atkinson et al. (2000) definem benchmarking como um método comparativo entre distintas organizações, buscando driblar os erros e as perdas com capital. Segundo os autores, esse método de valor atual, pode ser definida como uma fórmula de se estabelecer o valor presente de pagamentos ainda futuros descontados a uma taxa de juros corretos, subtraindo o custo do investimento inicial. Muito usado para cálculo de goodwill ou para demonstrações de moeda corrente, onde se tenta libertar das inflações.

De acordo com Padoveze (2000), a moeda constante pode ser vista como a transformação das demonstrações em outra uma moeda distinta, com certo grau de equilíbrio monetário tornando possível comparações ao longo do tempo. 
Atkinson et al. (2000), explica que o ponto de equilíbrio pode ser representado pelo nível de uma produção onde os custos são cobertos pelos lucros decorrentes das vendas, bens ou serviços. O autor cita ainda que ponto de equilíbrio é o momento em que as vendas ocorridas superam os custos fixos já comprometidos.

Com uma definição mais direta Martins (2003), afirma que o ponto de equilíbrio é o ponto em que os custos e despesas se igualam com a receita fazendo o lucro igual a zero.

\section{ECONOMIC VALUED ADDED (EVA)}

Para Atkinson et al. (2000), o Valor Econômico Agregado é utilizado como ferramenta para avaliação de desempenho.

Valor Econômico Adicionado = Lucro Contábil Ajustado (-) Custo de Capital x Nível de Investimento.

Segundo Cardoso et al. (2007), o Valor Econômico Agregado é o aprimoramento da utilização de recursos, com traços de análise de investimento. Determina a real lucratividade, o desempenho ao integrar uma cobrança sobre o lucro pelo custo de todo capital utilizado.

É uma função do conceito de custo de oportunidade do capital e da função de preservação do capital financeiro, afirma Padoveze (2000).

\section{FILOSOFIAS E MODELOS DE GESTÃO}

Cardoso et al. (2007), destacam como planejamento de ações futuras e controle das ações atuais, sendo uma ferramenta gerencial.

Para Padoveze (2000), orçamento é a expressão quantitativa de um plano e auxílio de ação e coordenação.

Segundo Gimenes e Bernard (2001), simulação é um sistema estruturado estrategicamente e seguido de tomada de decisões em torno de um plano, no qual os participantes assumem como principais gestores de uma empresa simulada.

Para Hansen e Mowen (2001), é o ato de descentralizar tomadas de decisões para categorias inferiores. De acordo com os autores, existem sete razões pelas quais as empresas decidem pela descentralização: o melhor acesso à informação local; limitações cognitivas; resposta em tempo mais oportuno; focalização da gestão central; 
treinamento e avaliação dos gestores de segmentos; motivação dos gestores de segmentos; e competição realçada.

De acordo com Cardoso et al. (2007), o Balanced Scorecard é um método de desempenho estratégico para várias áreas da organização. Segundo Padoveze (2000), compreende a missão e a estratégia da empresa num conjunto de medidas financeiras e não financeiras que serve de suporte para um sistema de medição e gestão estratégica.

Gestão Econômica compreende um modelo de gestão, decisão, mensuração e avaliação do resultado econômico, em uma administração por resultados econômicos, de acordo com Santos (2005).

Para Hansen e Mowen (2001), o objetivo da manufatura JIT (JUST IN TIME) é eliminar o desperdício e produzir apenas quando é necessário determinado produto, e somente em quantidades solicitadas pelos clientes. Focaliza na eliminação de desperdício ao reduzir tempo e o espaço.

Padoveze (2000) conceitua como administração de produção, JIT nasceu da visão de que os estoques são elementos estimuladores e disfarçados de inutilidade gerencial no processo fabril. Para ele as compras devem ser feitas no momento da necessidade da produção, processadas e entregues imediatamente aos clientes.

Para Hansen e Mowen (2001) o custeio Kaizen está preocupado com a redução dos custos e processos dos produtos existentes, ou seja, redução que não adicionam valor.

O controle da redução de custos é realizado em dois subciclos de uso repetitivo pela sequência de Planejar-Fazer-Verificar-Agir: ciclo de melhoria contínua e o ciclo de manutenção.

De acordo com Hansen e Mowen (2001), independente de criar e conservar uma vantagem competitiva, uma empresa deve assimilar toda cadeia de valores, e não somente a parcela na qual ela opera.

Para serem bem-sucedidas as estratégias de liderança em custos e de diferenciação é necessário desenvolver valores estrategicamente relevantes.

\section{ABORDAGEM INSTITUCIONAL}

Segundo Santana, Mário e Sediyama (2009), a teoria institucional, também conhecida como institucionalismo, tem seu alicerce na ciência política, na sociologia e na economia e estuda as inter-relações entre as organizações, os setores, estruturas normativas e culturais que cercam o meio organizacional, considerando que padrões de 
comportamento, sistemas de crenças e valores institucionalizados da sociedade influenciam as organizações, delineando-as e sustentando sua estrutura e suas ações.

Segundo DiMaggio e Powell (2005), o isomorfismo institucional é o processo que faz com que uma organização se assemelhe com outros que apresentem o mesmo método de condições ambientais. O isomorfismo é o resultado das pressões competitivas que forçam as organizações a adotarem formas adaptadas para ajudar na sua sobrevivência. Essas pressões institucionais externas e internas levam as organizações a adotarem comportamentos semelhantes. Assim, os autores entendem que o isomorfismo compõe um processo que influência uma organização a se assemelhar a outras do mesmo modelo ambiental, então passam a se tornar menos competitivas e eficientes, e mais semelhantes.

De acordo com Assis (2010), o isomorfismo pode ser entendido como uma centralização progressiva das organizações a uma aptidão por meio da imitação, buscando a legitimação.

Segundo Miller e Mcfarland (1987) a ignorância organizacional pode provocar nos indivíduos uma pressão onde eles possam se sentir pressionados a manterem a mesma posição em relação a um grupo, para que seja aceito.

Para compreender como a ignorância atua dentro das organizações, é necessário primeiramente conhecer seu conceito. Smithson (1989) compreende que a ignorância pode ser vista como algo incompleto ou uma falta ou extinção de conhecimento.

Davenport e Prusak (1998) admitem que é necessário e importante que uma organização compreenda sobre os conceitos e as ações da ignorância. Afirmam ainda que existe dentro das organizações o conhecimento é complicado, mesmo quem contratem pessoas inteligentes e que dialoguem entre si, afim de se tornarem mais ágeis e competitivas.

\section{PROCEDIMENTOS METODOLÓGICOS}

O objetivo geral dessa pesquisa é investigar a influência do isomorfismo institucional na adoção dos artefatos de contabilidade gerencial. E pode ser caracterizada como descritiva. Nesse tipo de survey, conforme afirmam Pinsonneault e Kraemer (1993), a hipótese não é contingente, no entanto busca verificar-se a percepção dos ocorridos está em conformidade com a realidade.

Quanto aos procedimentos, o trabalho classifica-se como survey, além de utilizar a análise de discurso e pesquisa bibliográfica. A pesquisa survey, segundo Pinsonneault 
e Kraemer (1993), é vista como a aquisição de dados sobre características, ações ou opiniões de grupo, usado para representar uma amostra do público, podendo ser um dos meios de pesquisa, os questionários.

Para Orlandi (2001), a análise do discurso não trata da escrita diretamente e como o próprio nome diz, trata do discurso. Essa metodologia utiliza da fala de uma pessoa para embasar suas análises e conceitos. A análise do discurso, como seu próprio nome indica, não trata da língua.

De acordo com Marconi e Lakatos (2007) a pesquisa bibliográfica, possibilita ao pesquisador uma relação mais direta com todo o material bibliográfico do tema abordado, além de ter como objetivo a discussão do tema sobre essas bibliografias já editadas.

Os dados foram coletados por meio de entrevista estruturada, de modo a contemplar teor interpretativo (VIEIRA; RIVERA, 2012) a esse trabalho. As entrevistas foram realizadas com 6(seis) funcionários de uma Cooperativa de Crédito do município de Caratinga-Minas Gerais. A escolha desta cooperativa deveu-se à intenção de dar continuidade ao trabalho de Boya (2012) que, possui um artigo publicado sobre a utilização dos artefatos gerenciais. Buscamos identificar se essa pesquisa se aplica em ramos diferentes das empresas já analisadas.

Inicialmente, foi enviada uma carta de apresentação aos diretores da empresa, para verificar a possibilidade da realização da entrevista. Foram solicitados para a entrevista o presidente, três gestores administrativos, o gerente de negócios, contador (a) e o supervisor de crédito.

As entrevistas foram colhidas por meio de gravação de voz de todos os representantes após autorização dos mesmos. Sendo feita de forma individualizada, sem acesso aos questionários e contando com a presença de três avaliadores (orientador e autoras).

O formulário de perguntas utilizado nas entrevistas constou de perguntas abertas e fechadas, previamente formuladas e distribuídas em cinco blocos. O Bloco1 buscou informações gerais sobre os respondentes; o Bloco 2 investigou os artefatos gerenciais utilizado pela cooperativa; o Bloco 3 identificou as motivações para o uso dos artefatos; o Bloco 4 discutiu sobre as atitudes e valores da cooperativa e o Bloco 5 questionou os fatores que influenciam a adoção ou abandono dos artefatos.

O formulário de perguntas que orientaram as entrevistas foi adaptado dos questionários utilizados no artigo de Boya (2012), tendo sido adicionadas questões 
abertas baseadas na revisão de literatura. Após serem coletadas, as entrevistas foram transcritas e organizadas. Em seguida, procedeu-se à análise dos dados e confronto com a literatura.

\section{APRESENTAÇÃO DE DADOS E ANÁLISE DE RESULTADOS}

No primeiro bloco de entrevistas, foram colhidas informações gerais sobre os respondentes, como o cargo ocupado por cada um dentro da cooperativa, o tempo exercido nessa função e a formação acadêmica em geral. Os resultados são demonstrados abaixo pelo Quadro 01:

Quadro 01: Informações gerais dos respondentes

\begin{tabular}{|c|c|c|c|}
\hline Respondentes & Cargo & $\begin{array}{c}\text { Tempo de } \\
\text { Função }\end{array}$ & Formação Acadêmica \\
\hline 1 & Presidente & 4 anos & Técnico em Contabilidade \\
\hline 2 & Diretor Administrativo & 3 anos & Ciências Contábeis \\
\hline 3 & $\begin{array}{l}\text { Gestor Administrativo- Área } \\
\text { Tributária }\end{array}$ & 7 anos & Direito \\
\hline 4 & Gerente de Negócios & 5 anos & Ciências Contábeis Contábeis \\
\hline 5 & Gestor Administrativo & 4 anos & Ciências Contábeis \\
\hline 6 & Controle Interno & 10 anos & $\begin{array}{l}\text { Ciências da Computação, Administração, Ciências } \\
\text { Contábeis }\end{array}$ \\
\hline 7 & Supervisor de Crédito & 6 anos & \multicolumn{2}{|c|}{} \\
\hline
\end{tabular}

Fonte: Dados da pesquisa

Todos os respondentes atuam na área de contabilidade, controladoria, finanças e possuem formação básica nessas áreas, com exceção de dois representantes: um com formação em Direito, e o outro com formação incompleta em Ciências Contábeis e Administração. Sobre atuação na cooperativa, somente três dos representantes atuam a 3 e 4 anos, os demais estão a mais de 5 anos, indicando grande experiência na função.

Ainda no primeiro bloco, os representantes foram indagados sobre as especializações e as instituições de ensino que frequentaram. O Quadro 02 demonstra as respostas:

\section{Quadro 02: Especializações e Instituições de Ensino}

\begin{tabular}{|c|c|c|c|}
\hline \multirow{2}{*}{$\begin{array}{c}\text { Represe } \\
\text { ntantes }\end{array}$} & Especializações & $\begin{array}{c}\text { Co } \\
\text { Instituições } \\
\text { nclusão }\end{array}$ & de Ensino \\
\hline 1 & Técnico em Contabilidade & 1995 & Não Informada \\
\hline 2 & Ciências Contábeis & 2003 & FIC \\
\hline
\end{tabular}




\begin{tabular}{|c|c|c|c|}
\cline { 2 - 4 } & MBA Gestão Empresarial & 2000 & FAGIG \\
\cline { 2 - 4 } & MBA Gestão Executiva & 2012 & UNIBAHIA \\
\hline \multirow{3}{*}{3} & Direito & 2000 & FIC \\
\cline { 2 - 4 } & Pós-Graduação em Gestão Executiva de Cooperativas & 2010 & UNIBAHIA \\
\hline \multirow{2}{*}{4} & Ciências Contábeis & 2010 & FIC \\
\hline \multirow{2}{*}{5} & Pós-Graduação em Auditoria e Perícia & Em curso & UNEC \\
\cline { 2 - 4 } & Ciências Contábeis & 2011 & FIC \\
\hline \multirow{3}{*}{6} & MBA Gestão de Pessoas e Negócios & Em curso & FIC \\
\cline { 2 - 4 } & Pós-Graduação em Gestão de Cooperativa e & 2004 & UFV \\
\cline { 2 - 4 } & Contabilidade & 2000 & FERP \\
\cline { 2 - 4 } & Licenciatura em Matemática & Incompleto & FIC \\
\cline { 2 - 4 } & Ciências da Computação & Em curso & UNEC \\
\cline { 2 - 4 } & Administração & & FIC \\
\hline
\end{tabular}

\section{Fonte: Dados da pesquisa}

As questões abordadas levam a identificar traços de isomorfismo normativo. Esses traços derivam da profissionalização e segundo DiMaggio e Powell (2005), as instituições de ensino por se assemelharem no quesito orientação e inclinação, são portadoras de mecanismos de condução do isomorfismo normativo. Indivíduos que frequentam uma mesma escola destinam-se a ter uma educação formal igual.

$\mathrm{Na}$ Cooperativa de Crédito analisada existe uma igualdade da instituição de ensino frequentada. De todos respondentes, apenas um dos sete, não estudou na FIC (Faculdades Integradas de Caratinga). Quase todos têm formação em Ciências Contábeis, exceto um dos respondentes que cursou Direito.

Partindo do pressuposto da Nova Sociologia Institucional e de que os respondentes estudaram na mesma instituição, e cursaram a mesma graduação esses aspectos indicam tendências de isomorfismo normativo, considerando que os respondentes, ao estudarem na mesma instituição e cursarem o mesmo curso, passam a se assemelharem em termos de orientação, assumindo, portanto, características isomórficas.

O segundo bloco da entrevista buscou identificar os artefatos gerenciais utilizados pela cooperativa. Os sete respondentes da cooperativa responderam, dentre os artefatos quais eram utilizados. As figuras abaixo demonstram o percentual da utilização de cada artefato segundo os representantes. 
Figura 01: Artefatos Gerenciais Utilizados pelas Empresa

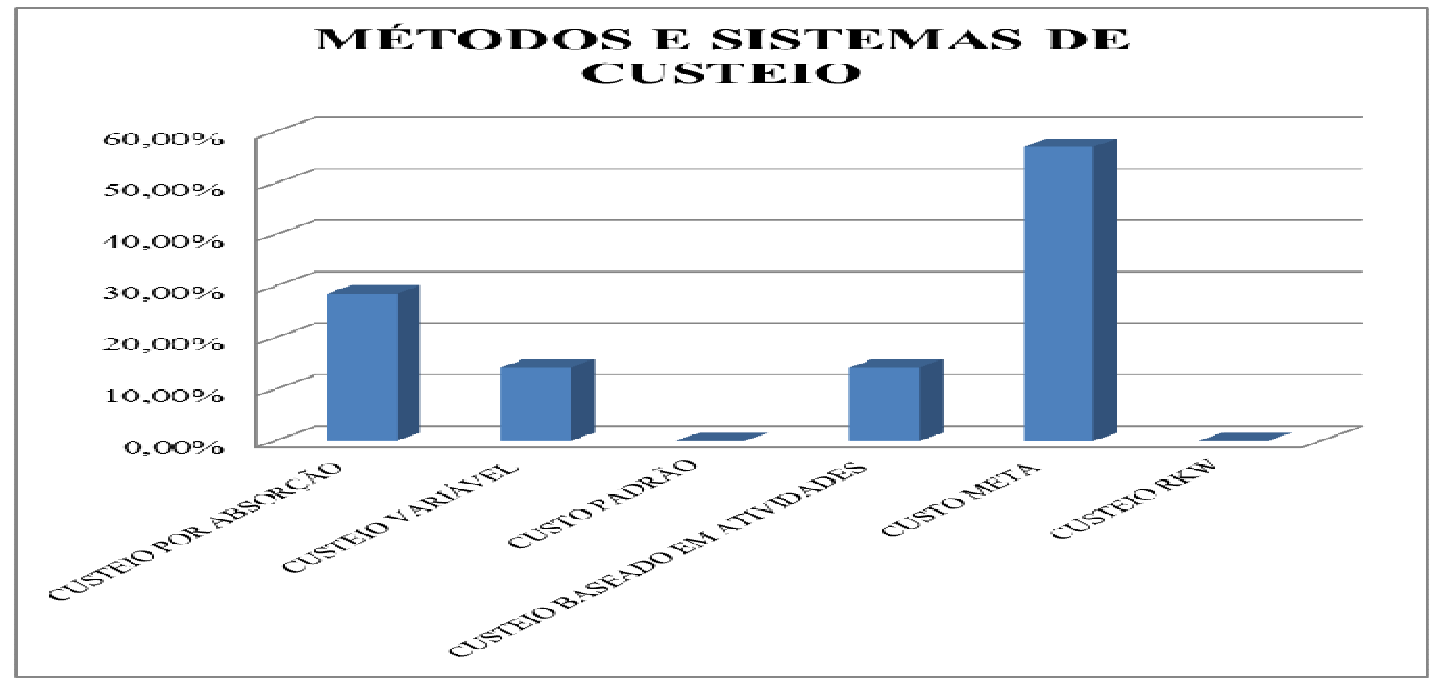

Fonte: Dados da pesquisa

Figura 02: Artefatos Gerenciais Utilizados pelas Empresa

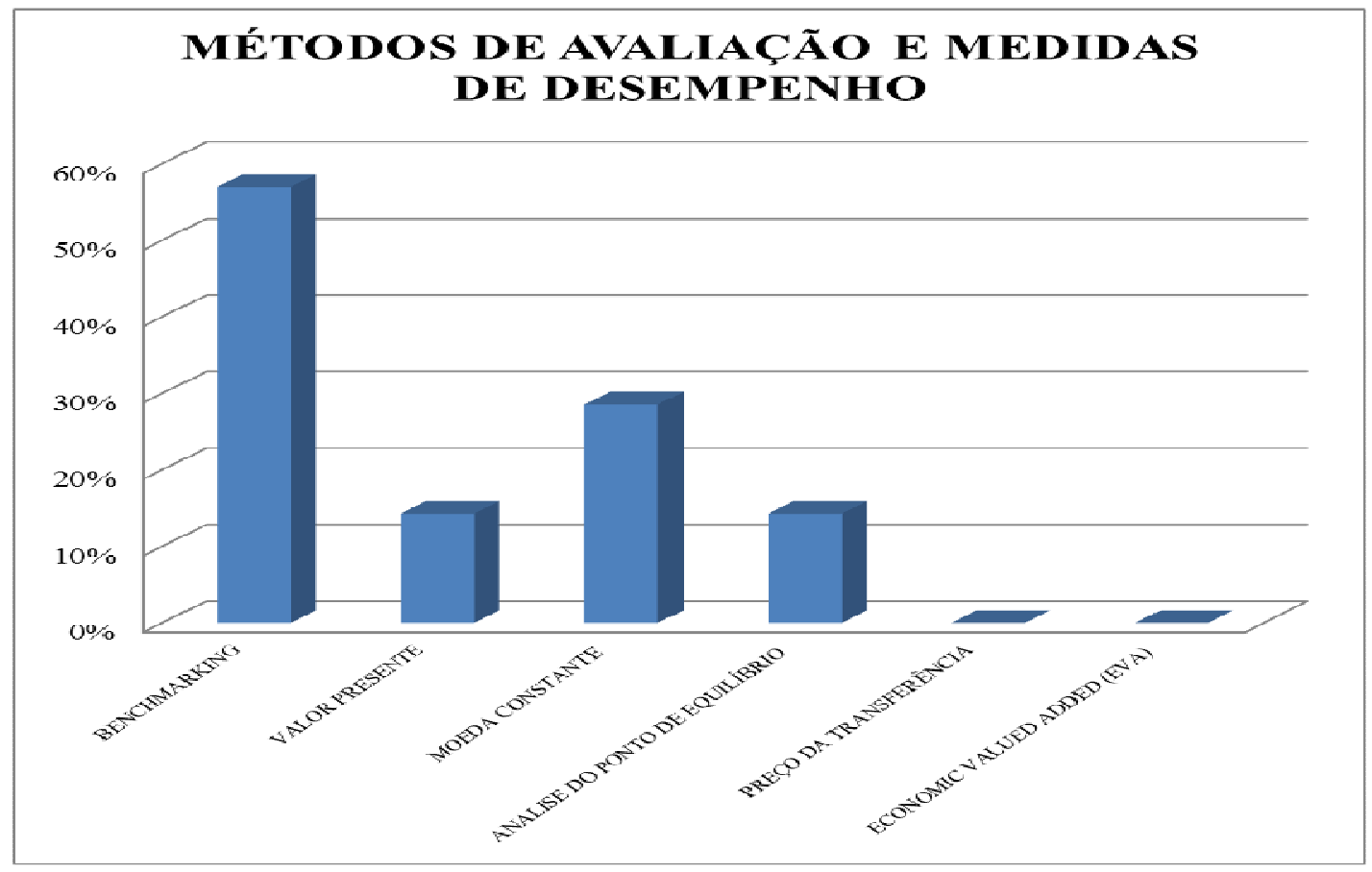

Fonte: Dados da pesquisa 
Figura 03: Artefatos Gerenciais Utilizados pela Empresa

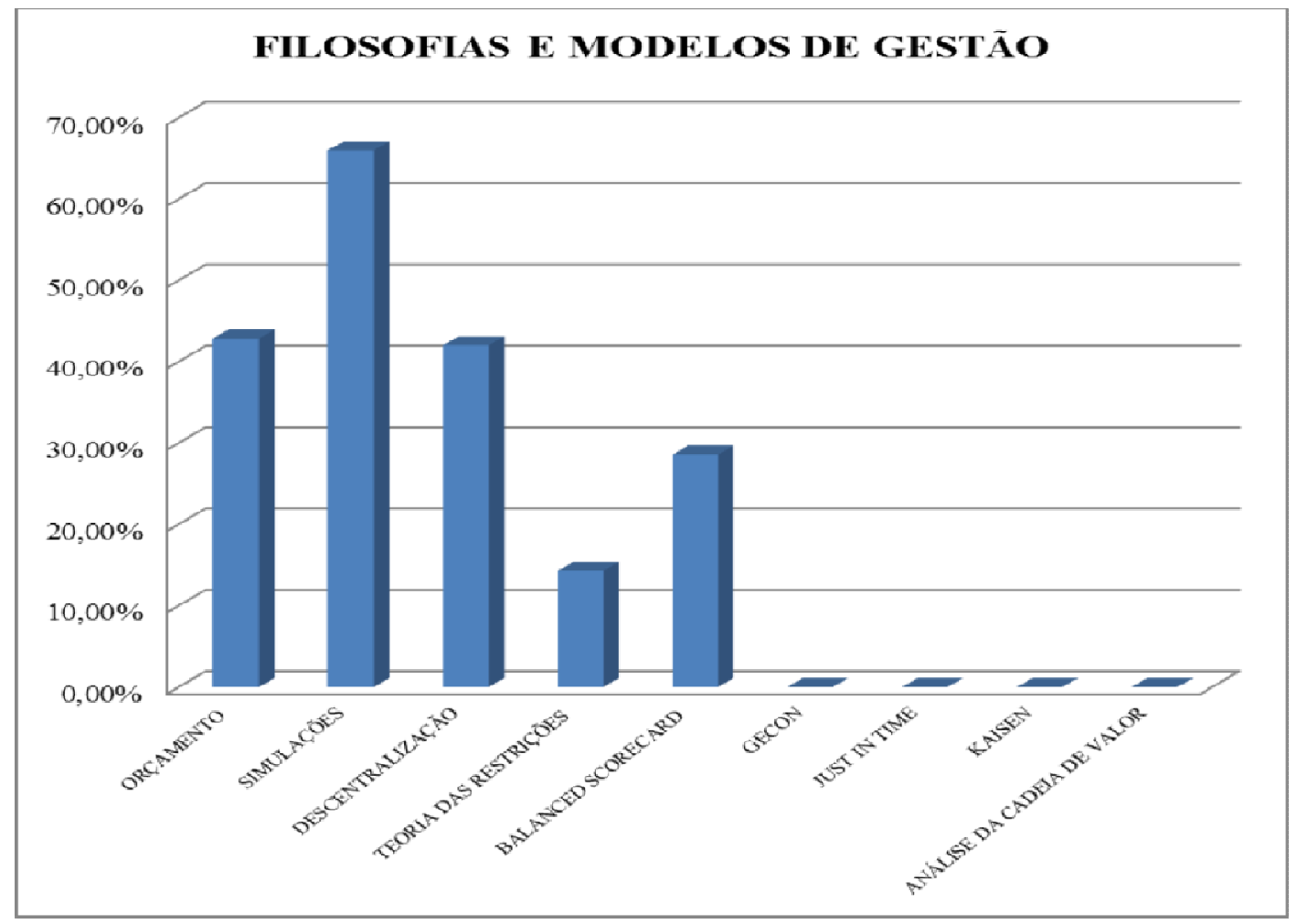

Fonte: Dados da pesquisa

Conforme pode ser observado nos quadros acima, a cooperativa utiliza, segundo os respondentes, 12 dos 20 artefatos citados na pesquisa. As respostas dadas partem de uma suposição, sendo que os respondentes não conseguem constatar de maneira confiável quais dos artefatos estão inseridos na cooperativa.

Abaixo seguem os quesitos com as devidas analises das respostas dadas:

Quesito 01- Métodos e Sistemas de Custeio: Os respondentes encontraram uma grande dificuldade em identificar qual era o método usado. A dúvida pode ser evidenciada pelo trecho extraído da entrevista com o Respondente 7: “[...] não consigo informar qual o método utilizado aqui na cooperativa”. Ainda assim os métodos mais citados foram o Custo Meta (57,14\%) e o Custeio por Absorção (28,57\%).

Quesito 02- Métodos e Avaliação de Medidas de Desempenho: Ficou evidente novamente a falta de informação dentro da cooperativa. Os respondentes apresentaram dúvidas, confirmadas pelas citações do Representante 3: "Nós do setor administrativo somos mais executores e não temos noção do quanto estamos gerando de rentabilidade. "e do Representante 2: "Temos dificuldade em avaliar o desempenho, falta profissionais para se empenhar nesse aspecto." 
O método mais votado pelos representantes foi o Benchmarking (57\%), e esse é o próprio isomorfismo mimético. Este tipo de isomorfismo deriva da incerteza que leva uma organização a imitar outras organizações tidas como bem-sucedidas, segundo DiMaggio e Powell (2005).

No entanto isso não se adequa no caso da Cooperativa de Crédito, partindo do ponto que existe uma ignorância de informação dentro da mesma. Por fim o Representante 3 fala em um trecho da entrevista sobre a medida de desempenho: "Nossa medida de performance é associada a variável tempo e não a variáveis econômicas. "

Quesito 03- Filosofias e Modelos de Gestão: Apesar de quatro dos métodos serem citados como usado, houve uma grande contradição de informações. Quando questionados sobre o método de Orçamentos três dos respondentes afirmaram que o método já era usado e o Representante 2 afirmou em um trecho da entrevista que: "Está sendo estudado a implantação do modelo orçamentário" e o Representante 3 também: "Estamos planejando em 2016 trabalhar com o método de Orçamentos. Até o momento trabalhávamos pelo método mais imediato.".

Outros métodos também foram citados pelos representantes como simulações, descentralização, teoria das restrições e balanced scorecard

No Bloco 3 foram elaboradas perguntas abertas, onde os representantes assinalaram concordando ou não com as afirmativas dispostas. O Quadro 07 abaixo demonstra em percentuais os resultados obtidos.

\section{Quadro 06: Atitudes e valores organizacionais}

\begin{tabular}{|c|c|c|}
\hline ATITUDES E VALORES ORGANIZACIONAIS & CONCORDO & $\begin{array}{c}\text { NÃO } \\
\text { CONCORDO }\end{array}$ \\
\hline 1. A empresa valoriza a introdução de novas técnicas do controle gerencial. & $100 \%$ & $0 \%$ \\
\hline $\begin{array}{l}\text { 2. A empresa tem como estratégia ser pioneira na adoção de técnicas } \\
\text { gerenciais. }\end{array}$ & $57 \%$ & $43 \%$ \\
\hline $\begin{array}{l}\text { 3. Considera que o ambiente organizacional deva sempre refletir as melhores } \\
\text { técnicas de controle gerencial adotadas no mercado. }\end{array}$ & $100 \%$ & $0 \%$ \\
\hline 4. O não uso de determinada técnica é fator importante para o seu abandono. & $100 \%$ & $0 \%$ \\
\hline 5. O apoio dos gerentes é importante para a implementação da técnica. & $86 \%$ & $14 \%$ \\
\hline 6. A empresa ao implementar uma nova técnica adota o nome consagrado. & $86 \%$ & $14 \%$ \\
\hline 7. A implementação de nova técnica é cuidadosamente planejada. & $86 \%$ & $14 \%$ \\
\hline 8. A comunicação da adoção da nova técnica é feita por meio de reuniões. & $100 \%$ & $0 \%$ \\
\hline 9. A introdução de novas técnicas é comunicada aos associados. & $57 \%$ & $43 \%$ \\
\hline $\begin{array}{l}\text { 10. A empresa acredita que os stakeholders valorizam novas técnicas } \\
\text { gerencias. }\end{array}$ & $100 \%$ & $0 \%$ \\
\hline
\end{tabular}

\section{Fonte: Dados da pesquisa}


A análise a seguir demonstra a opinião dos representantes para cada questão:

Questão 01: Os respondentes confirmam que a Cooperativa valoriza a adoção de novas técnicas

Questão 02: Nem todos os representantes acreditam que a cooperativa prefere ser pioneira na sua introdução de novas técnicas.

Questão 03: Consideram que o ambiente organizacional deva sempre refletir as melhores técnicas de controle gerencial adotadas no mercado

Questão 04: Os respondentes acreditam que o não uso de determinada ferramenta seja fator determinante para o seu abandono. O Respondente 2 ao ser questionado acrescenta seus dizeres citando "Em um determinado período fizemos a implantação de um mapa estratégico e por não obter resposta e não conseguir usá-lo como ferramenta, logo ele foi descartado”. Isso não pode ser caracterizado como isomorfismo, sendo que os representantes não têm certeza se todas os métodos assinalados são realmente usados como ferramenta gerencial.

Questão 05: Evidencia os esforços de legitimação dos artefatos por meio de simbolismos e rituais, como o apoio dos gerentes.

Questão 06: Os respondentes acreditam que a utilização de uma nova técnica adota sim um nome consagrado.

Questão 07: Os respondentes de uma maneira quase geral concordam com as perguntas. E quando perguntado sobre a questão 7, que trata sobre a implementação de novas técnicas, ela foi aprofundada pelo Respondente 3 que ressaltou: "As técnicas não são implantadas conforme deveriam ser, mas quando implantadas ou construídas recebem apoio".

Questão 08: Os respondentes afirmaram que as informações que são relevantes, geralmente são repassadas nas assembleias.

Questão 09: Sobre a comunicação, a introdução e valorização de novas técnicas perante os stakeholders, no caso da Cooperativa, aos associados, os respondentes citaram que essas informações são repassadas. Afirmaram ainda que alguns anos atrás os associados não conseguiam absorver essas informações, mas esse relacionamento tem sido mudado.

Questão 10: Segundo os respondentes os associados valorizam, já que o desejo deles é ver a empresa em crescimento. 
E por fim, no Bloco 5, os entrevistados foram solicitados a responderem sob os fatores que influenciam a adoção e abandono dos artefatos. O Quadro 03 abaixo traz a representação do percentual de importância de cada um.

\section{Quadro 03: Fatores que influenciam a adoção e abandono dos artefatos}

\begin{tabular}{|c|c|c|}
\hline $\begin{array}{l}\text { FATORES QUE INFLUENCIAM A ADOÇÃO E ABANDONO DOS } \\
\text { ARTEFATOS }\end{array}$ & IMPORTANTE & $\begin{array}{c}\text { NÃO } \\
\text { IMPORTANTE }\end{array}$ \\
\hline 1. A importância da matriz/assembleia/BANCOOB. & $100 \%$ & $0 \%$ \\
\hline 2. A importância clientes/fornecedores. & $86 \%$ & $14 \%$ \\
\hline 3. A credibilidade das práticas. & $100 \%$ & $0 \%$ \\
\hline 4. A experiência de outras cooperativas. & $100 \%$ & $0 \%$ \\
\hline 5. A opinião/recomendação das empresas de consultoria. & $57 \%$ & $43 \%$ \\
\hline 6. O desempenho econômico-financeiro. & $100 \%$ & $0 \%$ \\
\hline 7. A decisão do corpo diretivo e gerencial da empresa. & $100 \%$ & $0 \%$ \\
\hline 8. A imposição de órgãos reguladores. & $100 \%$ & $0 \%$ \\
\hline 9. A leitura de livros sobre o assunto. & $57 \%$ & $43 \%$ \\
\hline 10. O conhecimento obtido nas instituições de ensino. & $71 \%$ & $29 \%$ \\
\hline $\begin{array}{l}\text { 11. A opinião/recomendação das associações profissionais, como CRC, } \\
\text { IBRACON, AUDIBRA. }\end{array}$ & $29 \%$ & $71 \%$ \\
\hline
\end{tabular}

Fonte: Dados da pesquisa

A seguir, a opinião dos representantes para cada questão:

Questão 01: Tanto as assembleias quantos associados são vistos pelos representantes como de extrema importância para adoção ou abandono dos artefatos.

Questão 02: Segundo os representantes, clientes e fornecedores são de extrema importância para a cooperativa

Questão 03: Os representantes acreditam fielmente nas práticas, quando aderidas.

Questão 04: Afirmaram que a experiências de outras cooperativas, são observadas por eles no quesito gerencial.

Questão 05: Alguns respondentes citaram que nunca se remeteram aos serviços prestados por agências de consultoria.

Questão 06: O desenvolvimento econômico-financeiro é visto por eles com extrema influencia em relação ao uso ou não de artefatos gerenciais. Como foi citado pelo representante 3: "No momento temos sofrido com as conjunturas econômicas e estamos buscando novos meios de mitigar os danos que podem surgir”.

Questão 07: É de fundamental importância, visto que eles observam se isso irá trazer ganhos para a cooperativa. 
Questão 08: São sempre observados, a cooperativa não pode aderir uma técnica que vai contra a esses órgãos.

Questão 09: A leitura de livros sobre o assunto não é importante para influenciar a adoção ou abandono dos artefatos na Cooperativa.

Questão 10: Já o conhecimento obtido junto às instituições de ensino é considerado influência.

Questão 11: A imposição dos órgãos reguladores e a recomendação de associações são consideradas de fundamental importância segundo o

Representante 3: “As NBR'S, as auditorias contábeis que identificam níveis de deficiências, nos ajudam a observar a necessidade de implantar novas técnicas. "

\section{CONSIDERAÇÕES FINAIS}

Este trabalho teve como objetivo investigar a influência do isomorfismo institucional na adoção dos artefatos de contabilidade gerencial, correlacionando com a teoria da ignorância. Para se alcançar resultados buscou-se como objetivo específico, identificar os artefatos de contabilidade gerencial utilizados pela Cooperativa analisada.

Quanto ao objetivo específico, foi identificado que a Cooperativa de Crédito utiliza doze dos vinte artefatos apresentados. Com relação aos Métodos e Sistemas de Custeio, utiliza o ABC, Custo Meta, Custeio por Absorção e Custeio Variável. Entre os Métodos de Avaliação e Medidas de Desempenho apresentados, utiliza o Benchmarking, Valor Presente, Análise do Ponto de Equilíbrio e Moeda Constante.

Das Filosofias e Modelos de Gestão, utiliza o Orçamento, Simulações, Descentralização, Teoria das Restrições e o Balanced Scorecard.

Quanto à influência do isomorfismo institucional na adoção dos artefatos gerenciais, a partir dos resultados, pode-se concluir que existem traços de isomorfismo normativo decorrente da profissionalização, contudo esta forma de pressão isomórfica não é determinante na adoção dos artefatos de contabilidade gerencial. O que na verdade pode-se observar em relação aos artefatos, é que eles não sofrem com fatores isomórficos, considerando que existe uma incerteza entre os representantes de qual método é utilizado.

Através dos estudos de Harvey (2001), que criou o Paradoxo de Abilene, podemos entender melhor como funciona o processo de informações e tomada de decisão na Cooperativa. O autor cita que geralmente a empresas tomam decisões 
diferentes daquilo que realmente gostariam de fazer e dentre as formas citadas por ele, uma delas pode estar associada a cooperativa analisada. Com informações inválidas e imprecisas, os membros da organização tomam decisões coletivas que os levam a tomar atitudes contrárias ao que eles individualmente querem fazer, provocando ações contrárias aos interesses da própria organização.

Essa ignorância também estudada pelo autor da Teoria da Ignorância Deliberada, Smithson (1989), justifica o fato da cooperativa afirmando que isso ocorrerá porque a influência da incerteza (ignorância) sempre estará presente, provocando indecisões.

Espera-se que esse estudo possa incentivar outras pessoas, afim de que possam dar continuidade, testando outros modelos de organizações.

\section{REFERÊNCIAS}

ANDRADE, M. M. Introdução à metodologia do trabalho científico. $6^{\text {a }}$ ed. São Paulo: Atlas, 2003.

AQUiNO, A. C. B.; CARDOSO, R. L.; BOYA, V. L. A.; PAGLIARUSSI, M. S. Causality in a performance measurement model: a field study in a Brazilian power distribution company. Social Science Research Network, 2007.

AQUINO, A. C. B. Economia dos arranjos híbridos: o caso da coordenação de serviços em uma usina siderúrgica. 231f. Tese (Doutorado em Ciências Contábeis) Faculdade de Economia, Administração e Contabilidade de São Paulo. São Paulo, 2005. ASSAF NETO, A.; LIMA, F. G. Curso de Administração Financeira. São Paulo: Atlas, 2009.

ASSIS, L. B.; ANDRADE, J. O.; NETO, A. C.; TANURE, B.; CARRIERI, A.O Isomorfismo entre Executivos das Maiores Empresas Brasileiras. Revista Internacional de Psicologia, v.3, n.1, jan-jul, 2010.

ATKINSON, A. A.; BANKER, R. D.; KAPLAN, R. S.; YOUNG, S. M. Contabilidade Gerencial. Tradução de André Olímpio Mosselman Du Chenoy Castro. 2a ed. São Paulo: Atlas, 2000.

BEUREN, I. M.; NASCIMENTO, S.; FACHINI, G. J. Evidências de isomorfismo nas funções da controladoria das empresas familiares têxteis de Santa Catarina. Revista Contemporânea de Contabilidade, v. 7, n. 13, 2010.

CARdoso, R. L.; MÁRIO, P. C.; AQUINO, A. C. B. Contabilidade Gerencial: mensuração, monitoramento e incentivos. Atlas, São Paulo, 2007. 
CARMO, D. N.; BOYA, V. L. A.; FORTUNATO, L. O. A influência do isomorfismo institucional na adoção dos artefatos de Contabilidade Gerencial: o caso de duas empresas de grande porte. Revista Brasileira de Contabilidade, 2012.

CREPALDI, S. A. Contabilidade Gerencial: Teoria e prática. $5^{\text {a }}$ ed. São Paulo:Atlas, 2011.

COUTINHO, D. P. A teoria da informação: conceito de entropia e sua aplicação. 2004.

DAVENPORT, T.; PRUSAK, L. Working Knowledge. Cambridge, MA: Harvard Business School Press. 1998.

DIMAGGIO, P. J.; POWELL, W. W. A gaiola de ferro revisitada: isomorfismo institucional e racionalidade coletiva nos campos organizacionais. Revista de Administração de Empresas, v.45, n.2, abr-jun, 2005.

FREITAS, D. P. S.; QUARESMA, J. C. C.; SCHMIT, S. R. Z.; GONÇALVES, T. L.; QUINTANA, A. C. Contabilidade Ambiental: um estudo bibliométrico em revistas científicas brasileiras. Revista Ambiente Contábil, UFRN, Natal/RN, v. 4., n. 1, p. 7288, jan./jun. 2012.

FREZATTI, F. Agrupamentos dos Perfis da Contabilidade Gerencial no Brasil.UnB Contábil, Brasília, v.8, n.1, p.9-39, jan-jun, 2005.

GIL, A. C. Como elaborar projetos de pesquisa. $4^{\text {a }}$ ed. São Paulo: Atlas, 2002.171p.

GIMENES, R. M. T.; BERNARD, R. R. S. A utilização das técnicas de simulação empresarial associada a construção e aplicação de sistemas de informações gerenciais e de apoio às decisões no ensino da contabilidade gerencial. Revista Ciências Empresariais da UNIPAR, Toledo, v.2, n.1, p. 03-24, jan/jun, 2001.

GONZAGA, P. R.; LUZ, A.T. M; GUIMARÃES, T. N; VALERIO JUNIOR, V. B. Associação Entre as Práticas de Contabilidade Gerencial e Tamanho das Empresas: Um Estudo Empírico. In: CONGRESSO DA ASSOCIAÇÃO NACIONAL DOS PROGRAMAS DE PÓS-GRADUAÇÃO EM CIÊNCIAS CONTÁBEIS, n.4, SãoPaulo. 2010.

GUERREIRO, R.; FREZATI, F.; CASADO, T. Em busca de um melhor entendimento da contabilidade gerencial através da integração de conceitos da psicologia, cultura organizacional e teoria institucional. Revista de Contabilidade e Finanças, São Paulo, setembro, 2006.

HANSEN, D. R., MOWEN, MARYANNE M. Gestão de Custos: Contabilidade e Controle. $3^{\mathrm{a}}$ ed. São Paulo: Editora Cengage Learning, 2010. 
HARVEY, J. The Abilene Paradox: The Management of Agreement.Organizational Dynamics, 1974.

HARVEY, M.; NOVICEVIC, M.; BUCKLEY, M.;FERRIS, G. A historic perspective on organizational ignorance. JournalofManagerialPsychology. 2001.

HOPP, J. C.; LEITE H. P. O crepúsculo do lucro contábil. Revista de Administração de Empresas. Revista de Administração de Empresas. São Paulo, v.28, n.4, out-dez, 1988.

HORNGREN, C. T., Introdução à Contabilidade Gerencial. 5. ed. Rio de Janeiro:Prentice Hall do Brasil, 1985.

JOHNSON, H. T.; KAPLAN, R. S. A relevância da contabilidade de custos. $2^{\mathrm{a}}$ ed.Rio de Janeiro: Campus, 1996.

KERLINGER, F. N. Foundations of behavioral research. $3^{\mathrm{a}}$ ed. New York: Holt,Rinehart and Winton, 1986.

LAKATOS, E. M.; MARCONI, M. A. Metodologia científica. 5. ed.São Paulo: Atlas, 2007.

MARTINS, E. Contabilidade de custos. 9ª ed. São Paulo: Atlas, 2003.

MARTINS, G. A.; LINTZ, A. Guia para elaboração de monografias e trabalhos de conclusão de curso. São Paulo: Atlas, 2009.

MENDES, A. C. A.; TELES, J. Ignorância Organizacional:Desafios e Oportunidades de Pesquisa.EnAnpad, 2015.

MILLER, D.; MCFARLAND, C. Pluralistic Ignorance: When Similarity is Interpreted as Dissimilarity. Journal of Personality and Social Psychology. 1987.

MODELL, S. Institutional perspectives on cost allocations: integration andextension. The EuropeanAccoutingReview, v.11, n.4. 2002.

ORLANDI, E. P. Análise do discurso: princípios e procedimentos. $3^{\mathrm{a}}$ ed.Campinas: Pontes, 2001.

PADOVEZE, C. L. Contabilidade Gerencial: um enfoque em sistemas de informação Contábil; $3^{a}$ ed. São Paulo: Atlas, 2000.

PELEGRINI, C. H. Significado contemporâneo de teoria matemática da comunicação. Caderno.com, 4(2), 11-23. 2009.

PETTY, J.; SHARMA, R. Reforming the accounting stereotype: from management accountant to strategic business manager. A Profession Transforming: From Accounting to Management. Study 11 Issued by the IFAC-International Federation of Accountants, 2011. 
PINSONNEAULT, A.; KRAEMER, K.L. Survey research in management information systems: an assessment. Journal of Management Information System, 1993.

ROBERTS, J. Organizational ignorance: Towards a managerial perspective on the unknown. Management Learning, p. 215-236. 2013.

SANTANA, G. A. S.; MÁRIO, P. C.; SEDIYAMA, M. Y. N. Análise do orçamento sob uma abordagem teórica da perspectiva institucional. Revista deContabilidade e Controladoria. Paraná, v.1, n.3, 2009.

SANTOS, R. V. Controladoria: uma introdução ao sistema de gestão econômica.São Paulo: Saraiva, 2005.

SCAPENS, R. W. Never mind the gap: towards an institutional perspective on management accounting practice. Management Accounting Research, n.5. 1994.

SMITHSON, M. Ignorance and Uncertainty: Emerging Paradigms. Springer.1989.

SOUTES, D. O.; DE ZEN, M. J. C. M. Estágios evolutivos da contabilidade gerencial em empresas brasileiras. In: CONGRESSO USP DE CONTABILIDADE E CONTROLADORIA, n.5, 2005, São Paulo.

STEVENS, S. S. On the theory of scales of measurement. Science, v. 103, 1946.

TEN HAVE, S. Modelos de gestão: o que são e quando devem ser usados. Pearson Prentice Hall, 2003.

VIEIRA, A. M.; RIVERA, D. P. B. A Hermenêutica no Campo Organizacional: duas possibilidades interpretativistas de pesquisa. Revista Brasileira de Gestão de Negócios, v. 14, n. 44, p. 261-273, 2012. 